\title{
Comunicación

\section{Construyendo puentes: \\ la identidad de género de los \\ jefes de familia y la recepción televisiva}

\author{
AIMÉE VEGA MONTIEL ${ }^{1}$
}

El objetivo de este artículo es el de reflexionar en torno a las posibilidades de incorporar la categoría de género al análisis de procesos comunicativos. $\mathrm{El}$ fenómeno que observa es la recepción televisiva entre jefes de familia, en México. El supuesto central es que la identidad de género determina las formas particulares en que estos hombres se relacionan con la realidad social y con los otros, formas que pasan por la manera en que se conciben como ciudadanos, en la percepción que tienen de las esferas doméstica y pública y en cómo las vivencian, en cómo participan en los procesos comunicativos y, en este sentido, en cómo se relacionan con la televisión e interpretan los mensajes mediáticos.

PAlabRas Clave: género, jefe de familia, audiencia, recepción televisiva.
The main purpose of this work is to analyze the possibility of incorporate the category of gender in the reception analysis, by exploring how Mexican male heads of the family construct meaning of TV news. The hypothesis suggests that the identity of gender of this group of audience defines this communicative process.

KEY WORDS: gender, male head of the family, audience, T.V. reception.

1 Profesora investigadora de tiempo completo del Departamento de Comunicación del Tecnológico de Monterrey, Campus estado de México.

Correo electrónico: aimeevegamx@yahoo.com.mx 


\section{INTRODUCCIÓN}

En los años recientes, la categoría de género ha tomado relevancia en el análisis de los fenómenos sociales que se han desarrollado desde diversas disciplinas. Rescatar las relaciones, actividades y experiencias sociales del "ser mujer" o del "ser hombre", como eje clave para entender la forma en que se construyen los procesos socio-históricos, ha denotado las posibilidades de la perspectiva de género para elaborar una crítica transformadora y abrir nuevos debates y líneas de investigación.

Es pertinente reconocer que, en el campo de la Comunicación, las reflexiones que incorporan la categoría de género apenas se han desarrollado. Acorde con otras disciplinas sociales, los trabajos respecto al origen y validez del conocimiento han relegado la experiencia de los sujetos desde su situación de género. Por ello pienso que, incorporarla, posibilitaría la reformulación de fundamentos claves de nuestra disciplina (como ha sucedido en el caso de la Sociología, de la Antropología y de la propia Ciencia Política), al tiempo que puede resultar esclarecedora en el análisis de los fenómenos comunicativos.

En este tenor, el objetivo del presente trabajo es el de reflexionar en torno a las posibilidades de incorporar la categoría de género al análisis de procesos comunicativos. El fenómeno que observa esta investigación es la recepción televisiva entre jefes de familia, en México. El supuesto central del que parto es que la identidad de género determina las formas particulares en que estos hombres se relacionan con la realidad social y con los otros, formas que pasan por la manera en que se conciben como ciudadanos, en la percepción que tienen de las esferas doméstica y pública y en cómo las vivencian, en cómo participan en los procesos comunicativos y, en este sentido, en cómo se relacionan con la televisión e interpretan los mensajes mediáticos.

De esta forma, en la primera parte ubicaré conceptualmente este objeto de estudio. Se elaborará una definición del proceso de recepción televisiva, que surge del trabajo que en esta línea he venido desarrollando (Vega, 2004, 2004a), misma que comprende tres niveles, uno de los cuales (el individual) es el que contiene la categoría que aquí me ocupa, la de género. También explicaré la forma en que se construye la identidad de género desde la experiencia de los jefes de familia. En la segunda 
parte se anotarán algunas evidencias de la importancia de incluir esta categoría, a partir de las aportaciones derivadas de una investigación empírica llevada a cabo entre jefes de familia en México.

\section{DEL MARCO TEÓRICO-CONCEPTUAL}

\section{El proceso de recepción televisiva: hacia una definición}

Desde la óptica de los estudios de recepción -desarrollada por los Estudios culturales y el Análisis crítico de la recepción (Orozco, 1996; Lull, 1990; Jensen, 1987; Morley, 1980; 1986)- sabemos que, lejos de ser la mera representación de una relación causa (mensaje)-efecto (receptor) -óptica planteada por la corriente de los Efectos- este fenómeno comunicativo resulta un proceso de producción social de significado, que es llevada a cabo por los miembros de la audiencia, proceso en el que tiene una importancia clave el contexto en donde se construye el significado.

En este sentido, ambas perspectivas aluden a la recepción como un complejo proceso en el que convergen la actividad de las audiencias y la producción, emisión y circulación de los mensajes.

Específicamente, para el Análisis crítico, el concepto de audiencia implica el reconocimiento de la participación del sujeto en este proceso, de un sujeto al que se le define en una situación socio-histórica, individual y colectiva, determinada y distinta de los otros. En este tenor, y de acuerdo con Guillermo Orozco, la audiencia resulta no en una entidad homogénea, sino un mosaico de sujetos diferenciados por su género, edad, capital económico, cultural, educativo, por su etnia y por sus intereses concretos, entre otras variables. Lo que Orozco no niega es que a estas audiencias, o comunidades, las define su pertenencia sociocultural (Orozco, 1996).

Esta definición conceptual del término audiencia constituye una de las claves aportadas por la corriente del Análisis crítico, en tanto que ha permitido reconocer la capacidad de acción del sujeto y explorar empíricamente su poder para hacer, al mismo tiempo, un uso social de los medios, consumir y decodificar los mensajes. Al mismo tiempo, este concepto permite diferenciar al sujeto del concepto clásico de receptor, al que hacía alusión la perspectiva de los Efectos, desde el que se le 
definía como un objeto pasivo que no tomaba parte del proceso de recepción, más que como destinatario del mensaje.

De esta manera, el Análisis crítico asume el proceso de recepción como una relación entre audiencia y contenido y, por tanto, se ha centrado en analizar el o los procesos concretos en los cuales los discursos mediáticos se encuentran con las prácticas culturales de los sujetos (Jensen, 1992).

Por otro lado, y aunque se trata de un fenómeno que opera principalmente a escala micro, es pertinente reconocer que la recepción televisiva no se explica sólo en términos de la acción de los sujetos en sus contextos específicos, sino en tanto un proceso de transformación estructural que, si bien se visibiliza a través de las acciones particulares de los miembros de la audiencia, se encuentra en diálogo permanente con el contexto espacial y temporal en el que se integran las dimensiones micro y macro sociales. De esta manera, y siguiendo a James Lull (1990), en el proceso de recepción televisiva lo micro implica reconocer y analizar teórica y metodológicamente la actividad de la audiencia, y lo macro, la forma en que esta actividad se articula con un tipo de discurso social.

De esta manera, al ser conceptuado como un fenómeno socio-histórico que se manifiesta en las escalas micro y macro, al proceso de recepción televisiva se le puede reconocer afectado por distintos elementos o mediaciones (Martín-Barbero, 1990; Orozco, 1996). Unos, relacionados directamente con las formas en las que el discurso televisivo determina la manera en como será interpretado por los sujetos. Y otros, constituidos por una serie de elementos que tienen que ver con la situación particular de cada miembro de la audiencia: su nivel socioeconómico, educativo, edad, raza y género. Así también, por su conocimiento e intereses sobre temas específicos y por las construcciones temáticas a través de las cuales establece conexiones entre su mundo cotidiano y el mundo presentado por los medios de comunicación (Jensen, 1995). También por sus motivaciones, estrategias y hábitos de recepción (Martín-Barbero, 1990; Orozco, 1996), y por lo que ha sido denominado como las comunidades de interpretación (Jensen, 1987; Morley, 1980); es decir, por los espacios físicos y/simbólicos en los que la audiencia construye sentido de los mensajes mediáticos (como la familia, la escuela y el trabajo), comunidades en las que los líderes de opinión desempeñan un papel determinante en la interpretación que los sujetos hacen de la realidad social. 
Tomando como base estas claves, entiendo el proceso de recepción televisiva en tanto:

- Un acto social, porque es en la realidad social en donde se manifiesta.

- Un proceso activo, en movimiento, porque es cognoscitivo y reflexivo, en tanto que es un acto de producción de significado en el que participan los miembros de la audiencia y la propia televisión como productora de contenidos, discursos y cogniciones.

- $\quad Y$ un diálogo, en tanto que audiencia y televisión mantienen una interacción permanente, de ida y vuelta, de objetivos, informaciones, contenidos e intereses, que rebasa el límite espacio-temporal del acto de mirar televisión.

Definido de esta manera, como un fenómeno social, activo y dialógico, considero que el proceso de recepción televisiva requiere de un análisis integral que observe, por un lado, la forma en que las audiencias interpretan y se apropian de los mensajes televisivos, pero al mismo tiempo, los contenidos televisivos y el propio papel de este medio de comunicación, en tanto que se trata de una institución que forma parte de una estructura económica y política bien definida y que desempeña un importante rol, en cuanto productora de discursos, en la conformación de las audiencias como sujetos sociales.

\section{Articulando un modelo para el análisis integral} de la recepción televisiva

Mirar la recepción televisiva como un proceso social complejo, que se manifiesta a nivel macro y micro y que involucra la participación de, por lo menos, dos actores centrales, me lleva a asumir que no es posible construir una forma unívoca de analizarlo. Más bien, sugiere proponer un esquema metodológico (ver Cuadro 1) que permita entender cuáles son los elementos que median este proceso y la importancia de cada uno. Partiendo de esta premisa, considero que un estudio integral del proceso de recepción televisiva implica tres dimensiones básicas de observación: una individual, una televisiva y una social-institucional:

1) La dimensión individual hace alusión a las audiencias, es decir, a los sujetos concretos (en este caso, a los hombres jefes de familia). La 
encuentro asociada a los factores que vuelven a cada sujeto único, que le determinan una identidad particular y que lo ubican en realidades concretas. Entiendo que estos elementos inciden en la forma en que construirá un significado concreto a los mensajes televisivos. Esta dimensión se divide a su vez en dos escalas básicas: una que he denominado estructural y que alude a los elementos que le determinan una identidad específica al sujeto: la edad, el nivel escolar, la raza y la ubicación en la esfera socio-económica y, particularmente, a los factores socio-históricos que le definen su identidad de género. La otra escala que corresponde a esta dimensión es la perceptiva, que se refiere a los esquemas cognoscitivos del sujeto. Esta escala implica los conocimientos con los que participa en este proceso, así como sus intereses y opiniones, sus expectativas, anhelos y deseos.

2) La dimensión televisiva se refiere al papel de la televisión como visibilizadora de los actores y de las discusiones, opiniones e interpretaciones pertenecientes a la esfera pública y como fuente clave en la construcción de conocimiento que sobre esta realidad hacen los sujetos. Esta dimensión implica una escala formal, que se refiere al análisis de los discursos televisivos. Y comprende también una escala interpretativa, que comporta analizar la interpretación que de esos mensajes hacen los sujetos (que va de conocer los elementos que determinan su elección por determinados programas, así como sus prácticas y hábitos de recepción particulares).

3) La dimensión social-institucional implica reconocer que el sujeto es un participante activo en diversas instituciones sociales al mismo tiempo: la familia, la escuela, el trabajo, las asociaciones civiles, los partidos políticos, etcétera. Se entiende que estos escenarios son contextos que proveen al sujeto de elementos (conocimientos, definiciones e interpretaciones) que le ayudan a producir un significado de los mensajes televisivos. Esta dimensión comprende una escala social.

La categoría de género

Dentro de las categorías que se observan en esta definición conceptual para un análisis integral de la recepción televisiva (Vega, 2004), es sobre la de género que vale centrar nuestro interés. 


\begin{tabular}{|c|c|c|}
\hline \multicolumn{3}{|c|}{$\begin{array}{c}\text { CUADRO } 1 \\
\text { MODELO PARA EL ANÁLISIS INTEGRAL DEL PROCESO } \\
\text { DE RECEPCIÓN TELEVISIVA }\end{array}$} \\
\hline \multirow{3}{*}{$\begin{array}{l}\text { Dimensión } \\
\text { Individual }\end{array}$} & Escala & Categorías \\
\hline & -De referencia & $\begin{array}{l}\text { Género/Edad/Escolaridad/ } \\
\text { Posición socioeconómica }\end{array}$ \\
\hline & -Perceptiva & $\begin{array}{l}\text { Cognoscitiva/Afectiva/Valorativa/ } \\
\text { Subjetiva }\end{array}$ \\
\hline \multirow[t]{2}{*}{ Televisiva } & -Formal & $\begin{array}{l}\text { - Posicionamiento de los receptores } \\
\text { - Construcción de la realidad }\end{array}$ \\
\hline & - Interpretativa & $\begin{array}{l}\text { - Elección-Consumo } \\
\text { - Prácticas de comunicación } \\
\text { y hábitos de recepción } \\
\text { - Construcción de significado }\end{array}$ \\
\hline $\begin{array}{l}\text { Social- } \\
\text { Institucional }\end{array}$ & -Social & $\begin{array}{l}\text { - Comunidades interpretativas } \\
\text { - Líderes de opinión }\end{array}$ \\
\hline
\end{tabular}

Fuente: Elaboración propia (ver: Vega, 2004)

Como perspectiva, el género es una línea de análisis que permite observar que detrás de las diferencias sexuales entre "ser mujer" y "ser hombre" se han construido desigualdades sociales, políticas, económicas y culturales entre mujeres y hombres.

La perspectiva de género abre la posibilidad de entender la formación de la identidad como producto de un largo proceso que se va construyendo desde que se espera el nacimiento de una hija o un hijo. Se inicia con discursos y con acciones sociales sobre cómo se nombra y lo que se espera de las personas. Este horizonte cultural es el que abre o cierra ciertas posibilidades de vida para las mujeres y los hombres, es decir, los mandatos.

Así, las identidades de género resultan en construcciones discursivas que surgen en sociedades estructuradas con base en relaciones asimétricas entre los sexos. Esta asimetría consiste en designar diferenciaciones de modo tal que tareas y funciones asignadas a hombres y mujeres, al igual que otros atributos como el prestigio y el poder, no guardan la misma proporción o no son comparables (Ramírez, 1993). Género resulta ser entonces la construcción social de la diferencia entre los sexos, el sexo socialmente construido, dinámica en la cual las ideologías masculinas constituyen su expresión en la subjetividad de hombres y mujeres. 
Esta diferenciación vuelve manifiesta, de acuerdo con Pierre Bourdieu (2000), la dominación masculina en tanto la manifestación más clara de la existencia de las relaciones entre hombres (dominadores) y mujeres (dominados), y que hace aparecer como naturales y aceptables las relaciones de dominación entre los géneros. Esta dominación masculina, entendida como la incorporación del habitus de género, ${ }^{2}$ en la cual los sujetos introducen inconscientemente el orden simbólico androcéntrico, es consecuencia de la violencia simbólica, una violencia que es "amortiguada, insensible e invisible para sus propias víctimas, que se ejerce esencialmente a través de los caminos puramente simbólicos de la comunicación y del conocimiento, del reconocimiento y del sentimiento" (Bourdieu, 2000:12).

Esta forma de violencia simbólica es reconocida y apropiada por dominadores y dominados, lo que ha hecho posible la producción y reproducción de la superioridad masculina -y por tanto, de la inferioridad de las mujeres- como eje del orden en el mundo moderno. Dicha desigualdad ha encontrado sus argumentos en el ámbito biológico y en el cultural para clasificar todas las prácticas de acuerdo a distinciones reducibles a la oposición entre lo masculino y lo femenino (alto/bajo, dentro/afuera, adelante/atrás, derecha/izquierda, derecho/curvo, seco/ húmedo, duro/blando, picante/insípido, claro/oscuro), lo que se ha constituido como un recurso clave de organización social.

En este orden de ideas es importante anotar, sin embargo, que el hecho de que sean las mujeres las víctimas visibles de este sistema de dominación, no significa que sean ellas las únicas prisioneras de tal estructura: los hombres también se encuentran sometidos a estas pautas culturales, pues son obligados a asumir y a demostrar permanentemente su virilidad, como será visto a continuación.

\section{Del mandato: ¿qué significa ser un jefe de familia?}

En el modelo hegemónico, la sociedad exige a los hombres pasar por pruebas que den cuenta de su capacidad para acceder a la cualidad más deseada

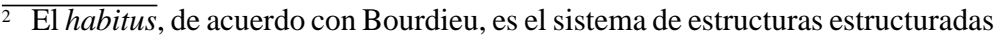
que funcionan como estructuras estructurantes, en este sentido, de lo que es la feminidad y la masculinidad. 
y al mismo tiempo más difícil de alcanzar: la masculinidad. En este tenor, la condición masculina se encuentra constantemente en duda, por lo que se exige al varón que pruebe a lo largo de su vida, mediante su afirmación social y personal, que es poseedor de esta cualidad. Es así como la sociedad establece pautas, rituales, pruebas, sistemas de premios y castigos que estimulan la conducta agresiva y activa del varón, inhibiendo al mismo tiempo sus comportamientos pasivos. Y dado que el cumplimiento de este mandato resulta en un proceso harto complicado, el beneficio que se recibe a cambio es el más preciado por el pensamiento moderno: la posibilidad de ejercer poder y con ello el privilegio de "ser importante".

En este orden de ideas, el primer y más importante mandato que un varón debe asumir, para demostrar su masculinidad, es el de ser un jefe de familia. El modelo tradicional define al jefe de familia como un sujeto que, en sí mismo, articula derechos ("mandarse solo") y deberes (ser protector), libertad y determinación, potencia y autoritarismo. Bajo este precepto, el varón constituye la base individual de la sociedad y su labor es la de sostenerla. Es una identidad construida a partir de su función de sostenedor y protector del hogar, al tiempo que el proveedor del alimento para su familia. Y el premio que recibirá por el cumplimiento de este mandato será el privilegio del poder y su predominio en la esfera pública.

Por otro lado, desde esta perspectiva domina la lógica de que los varones se hacen a sí mismos y que su identidad de género se construye sobre un límite estricto entre público y privado, donde calle y casa representan mundos regidos por códigos particulares y unidos por un modelo de roles complementarios en virtud de los cuales el varón puede ejercer sus privilegios en la calle a condición de cumplir con sus obligaciones en el hogar (que, hay que decirlo, también constituye para él un espacio de privilegios). De esta manera, la ecuación resulta en jefes de familia que resuman las fuerzas de la naturaleza y que sean al mismo tiempo:

Tesoneros, pródigos, brutos, cariñosos, soberbios, egoístas, generosos, previsores, incautos, indiferentes, exuberantes, corajudos, infieles, versátiles, ingeniosos y encantadores (Abarca, 2005).

Desde esta lógica, en el hogar, el jefe de familia será entonces el padre-sofá , que asumirá este espacio como un lugar de descanso hasta 
la nueva partida, donde se le deberá nutrir, servir, respetar y satisfacer. Es el padre despreciativo, el pedagogo brutal de la autonomía masculina que transmite lo que a su juicio representa la primera enseñanza de un varón: "Si no aprendes a nadar, te ahogas" (Abarca, 1999).

De esta forma, estas construcciones sociales de lo que es ser un jefe de familia es lo que definirá a estos hombres la manera en que se relacionen con la realidad social, en las esferas doméstica y pública, en la auto-percepción de su ciudadanía y, en el tema de análisis que aquí me ocupa, en la forma en que se relacionan con la televisión y con los mensajes que ésta produce.

Revisemos pues algunas evidencias de las posibilidades que representa incluir esta categoría en el análisis empírico de procesos comunicativos.

\section{APUNTES METODOLÓGICOS}

Los datos que a continuación se discuten derivan del trabajo empírico que he desarrollado en México y que ha tenido como principal objetivo analizar la relación entre la recepción de noticias sobre el proceso electoral del 2000, emitidas por los telediarios mexicanos, y la decisión de voto de los jefes de familia. La pregunta eje de esta investigación ha sido:

- ¿ ¿De qué manera, el acto de mirar telediarios contribuye a que los jefes de familia: a) Conozcan y entiendan un proceso político, b) decidan su voto, y c) conciban sus acciones, identidad y participación política?

La estrategia metodológica ha considerado al grupo de audiencia de los jefes de familia, residentes en el Distrito Federal y el área metropolitana, con rangos de edad entre los 25 y los 35 años de edad. ${ }^{3}$ Se determinó trabajar con hombres que contaran con un nivel escolar básico y que pertenecieran al sector socioeconómico bajo, dado que en él se concentra la mayor densidad de esta población. ${ }^{4}$

3 De acuerdo con cifras del Instituto Nacional de Estadística, Geografía e Informática, INEGI, en el año 2000 estaban registrados un total de 17 millones 671,681 jefes de familia en México, de los cuales 1 millón 618,625 residen en el Distrito Federal. La franja de densidad más alta entre dicha población se halla entre los 25 y los 34 años de edad (INEGI, 2000).

4 Estos criterios demográficos para la selección del grupo de audiencia han obedecido también a las exigencias de la técnica del grupo de discusión, en la 
La herramienta metodológica ha sido el grupo de discusión. Se decidió el empleo de esta técnica porque su dinámica permite que fluya la conversación grupal de manera natural, lo que posibilita conocer las opiniones de los sujetos tal y como las vierten en un espacio social natural, frente a otros con los que pueden compartir ideas, sentimientos y necesidades comunes, pero que también pueden tener diferentes posiciones frente al tema. Así también, se echó mano de este recurso porque el objetivo de la investigación ha sido el de comprender el uso y la relación de este grupo de audiencia con los mensajes televisivos. No se buscó verificar ni cuantificar el fenómeno. Esta herramienta ha dado la posibilidad de entender la complejidad y el significado de este problema de investigación en las propias palabras de las hombres y de la discusión detonada en las sesiones, algo que la cuantificación no permite.

En las siguientes líneas se discutirán algunos hallazgos en torno al papel que desempeña la identidad de género en el proceso de recepción de noticiarios de televisión entre jefes de familia mexicanos. Para este propósito me centraré en la exposición de los siguientes temas, derivados de las categorías de nuestro Modelo de análisis (Cuadro 1): fuentes de información, motivación para mirar los telediarios, contexto y hábitos de recepción, comunidades de interpretación y líderes de opinión.

\section{LOS HALLAZGOS}

\section{De sus fuentes de información}

He señalado que el contexto particular en el que se han recogido los datos empíricos ha sido el del proceso electoral celebrado en el año 2000. Entiendo que es por esta razón que los participantes, sin distinción de edad o nivel escolar, han destacado la importancia que tiene para ellos informarse sobre lo que acontece en la política nacional, teniendo como principal fuente de información a los medios de comunicación.

que, con el objetivo de garantizar la participación de todos los sujetos durante una sesión, es condición fundamental que no se entremezclen personas de generaciones muy diferentes, ni con niveles socioeconómicos muy desiguales y preferentemente del mismo sexo. 
Entre este grupo de recepción, la lectura de algún diario ocupa un lugar privilegiado: lo hacen de camino al trabajo, sea en el auto o en el transporte público, o al final de la jornada laboral, una vez que están descansando en el hogar. Los jefes de familia entrevistados dicen preferir los diarios deportivos, mismos que incluyen una sección de información general que les permite saber lo que pasa en el país. En este tenor, afirman que son ellos quienes eligen el diario que otros miembros de la familia (incluidas por supuesto las amas de casa) leen, dado que son ellos quienes lo llevan al hogar.

De todos los medios de comunicación, el que se erige como la principal fuente de información sobre la política para estos hombres es la televisión. La mayoría de los participantes afirma tenerla como la vía principal para saber de la política nacional y concretamente de las campañas presidenciales. ¿Por qué privilegiar a este medio?: por su inmediatez. Es más fácil enterarse de las campañas presidenciales a través de la televisión.

De todos los formatos, son los telediarios los programas más atendidos por los jefes de familia. Dicen mirarlos con regularidad, casi a diario. De todas las emisiones, los nocturnos resultan ser los más vistos: "Noticiero" y "Hechos".

Entre los jefes de familia, "Noticiero", que es conducido por Joaquín López Dóriga, es el más visto, aunque tienen una posición crítica ante el programa pues consideran que representa la voz oficial. El otro telediario de su preferencia es "Hechos", pero no la emisión estelar que es dirigida por Javier Alatorre, sino el que encabeza Pablo Latapí, en Canal 7. ¿La razón? El horario: se transmite a las 9 de la noche y eso les da la posibilidad de ir a dormir pronto para levantarse temprano al día siguiente. En este tenor, afirman que la emisión de Alatorre presenta las mismas noticias, por lo que no consideran necesario tener que esperar a su transmisión (10:30 de la noche) para enterarse de lo que sucede.

Cabe señalar que, aun cuando constituyen su principal fuente de información, estos telediarios encuentran un nivel muy bajo de credibilidad entre este grupo de audiencia. La mayoría de los participantes opina que existe una relación de "complicidad" entre los empresarios de la televisión y la clase política, que no permite pensar que la manera en la que estos telediarios hacen visible la política es apegada a la objetividad 
y mucho menos a la transparencia. De esta manera, es evidente su escepticismo en torno a la veracidad de las noticias.

\section{De sus motivos}

La primera razón que motiva a estos jefes de familia a mirar los telediarios es la de informarse. La consideran parte de un deber ser ciudadano. Hacen referencia a esta actividad como si se tratara de una obligación, como algo que se "tiene" que hacer. Así también, mirar los noticiarios forma parte de su vida cotidiana.

Para estos hombres, la elección del telediario depende de los siguientes factores:

- Que informe oportunamente de los acontecimientos.

- Que refleje de manera fiel los hechos, cuidando de no caer en el amarillismo.

- La imparcialidad frente a los distintos actores políticos.

- La inteligencia del conductor, así como su honestidad y franqueza.

- Y la objetividad de la propia televisora.

Una cualidad que los participantes destacan de estos programas, comparándolos con otras fuentes, es que les proporcionan la información de manera resumida. Consideran que es más fácil enterarse a través de los telediarios porque les permite obtener un panorama general de lo que ha sucedido a lo largo del día, sin que tengan que invertir mucho tiempo en ello. La mayoría valora positivamente el resumen introductorio de estos programas de noticias, porque les posibilita enterarse en muy pocos minutos de la información más importante.

Por último, y como señalaba líneas arriba, el locutor comporta una buena razón para mirar el telediario. En este sentido, para los jefes de familia es importante que este personaje sea honesto e inteligente y que en su personalidad se resuman las principales cualidades de ser un varón: seguridad, sinceridad, decisión y liderazgo en sus opiniones.

\section{De sus contextos y sus hábitos}

Como lo señalan David Morley (1986) y Roger Silverstone (1996), el hogar, como el centro de la vida cotidiana, constituye el marco princi- 
pal en el cual se desarrolla el acto de mirar televisión. Los hallazgos de este estudio así lo corroboran. Para todos los participantes, es su casa el primer escenario en donde la recepción de los telediarios toma forma.

Los espacios concretos dentro del hogar en los que este grupo de audiencia prefiere mirar estos programas son diversos. La sala es el marco principal en el que ven los noticiarios. De acuerdo con Morley (1986), es éste el escenario familiar más importante. Es el lugar de encuentro entre los miembros de la familia, en donde comparten y comentan su vida diaria. En esta socialización, la televisión forma parte fundamental. Su presencia en la sala de los hogares que habitan los participantes se da, pues, por descontada.

Una pregunta central para los fines de esta investigación consistió en saber si existía un sofá que destacara como el privilegiado en el hogar, así como la identidad de su ocupante habitual. La respuesta general fue que, en efecto, el sofá existe y que está colocado frente al televisor. Que su ocupante principal es el jefe de familia o, en su ausencia, sus hijos, pero nunca o casi nunca es el ama de casa quien se sienta en él a mirar televisión.

Por otro lado, para estos sujetos, la actividad de mirar los telediarios es esencialmente social, la consideran una actividad que valoran como positiva en tanto que estos programas proponen a la familia temas acerca de los cuales discutir. En este sentido, como lo han observado otros trabajos (Morley, 1986; Lull, 1990), es la familia el núcleo central entre la televisión y la vida cotidiana.

En lo relativo a sus hábitos de recepción, esta investigación evidencia que se ven determinados por la situación particular de género de estos hombres. En este sentido, y dado que el hogar representa para el varón un lugar de ocio, en el que se le nutre, sirve, respeta y satisface (labor que le corresponde desarrollar a las amas de casa), los jefes de familia entrevistados dicen destinar un tiempo y atención específicos a mirar estos programas, interrumpidos tal vez sólo por el bocado que dan a su cena. En contraste, la mujer ama de casa difícilmente tiene la oportunidad de mirar con atención los noticiarios, dado que para ellas el hogar es un espacio de trabajo permanente que les demanda satisfacer las necesidades vitales de los otros (Vega, 2004b). 
Por otro lado, las relaciones de poder son clave en los hábitos de recepción de los programas de noticias entre este grupo de audiencia. Si partimos de que en el seno de la sociedad masculina, el poder pertenece a los hombres, este mismo orden se traslada al espacio doméstico.

En la mayoría de los casos, sin distinción por género, es el jefe de familia quien elige el noticiario que se mira en la casa. En segundo lugar, son los hijos varones. Después, son las hijas cuando son adolescentes o jóvenes. Al final de la lista, son las amas de casa quienes lo escogen. La explicación que los participantes de esta investigación encuentran es porque reconocen que son ellos, los jefes de familia, quienes tienen más conocimiento sobre los temas, puesto que pasan la mayor parte del día en el espacio público lo que les da la posibilidad de adquirir conocimientos y experiencias a los que difícilmente tienen acceso quienes pertenecen al espacio doméstico (es decir, las amas de casa), y ello les da la autoridad para elegir qué noticiario mirar. Hay pues un autorreconocimiento implícito de que son ellos los que saben.

El poder se hace aún más evidente en el caso de las televisiones con control remoto: es el jefe de familia quien lo manipula,

Yo agarro el control porque soy quien lo sabe manejar.

La posibilidad que da el control remoto de hacer "zapping" constituye una de las actividades favoritas de estos hombres al momento de mirar los telediarios. De acuerdo con sus testimonios, lo hacen con el objetivo de comparar la oferta de contenidos entre las televisoras:

Cuando están dando la noticia le cambias para ver si la otra está más interesante y te mantienes atento, y cuando son intrascendentes mejor le cambias.

En este sentido, como lo han señalado otros trabajos sobre recepción televisiva (Lull, 1990; Morley, 1986), el poder masculino en la familia en relación con estos hábitos particulares de mirar televisión, no son simplemente características del ser hombre: se constituyen también como elementos que definen la construcción socio-histórica de la masculinidad. 


\section{De sus comunidades y sus líderes}

Las comunidades de recepción, como los espacios de socialización en los cuales los grupos de recepción intercambian habitualmente sus apropiaciones de los mensajes y se reapropian de ellos hasta lograr significaciones más definitivas, resultan determinantes. Estos espacios son tan diversos como cada sujeto; sin embargo, en esta investigación, la identidad de género se hace evidente en la elección de comunidades entre este grupo de audiencia.

Para los jefes de familia, sus comunidades interpretativas se hallan muy alejadas del hogar, es decir, en la esfera pública. De esta manera, lugares como el transporte público, mientras se trasladan a su lugar de trabajo, les representan espacios para discutir sobre las noticias que miran por televisión, y más cuando se trata de informaciones relativas a la política nacional.

Pero son fundamentalmente el trabajo y las reuniones con amigos -sean en el gimnasio o en el bar- los espacios que más valoran para intercambiar informaciones y opiniones con los otros.

$\mathrm{Y}$ es en estas comunidades de recepción en donde los jefes de familia identifican habitualmente a los líderes de opinión. Esos personajes a quienes les adjudican un reconocimiento especial -sea porque tienen acceso a información privilegiada, sea porque tienen el reconocimiento generalizado de los otros para opinar-.

Para los hombres, estos líderes se hallan de nuevo en la esfera pública y, además, en figuras masculinas y nunca en femeninas: en los noticiarios de televisión reconocen a sus conductores, en sus lugares de trabajo reconocen a sus jefes, en sus familias reconocen al padre o a sus hermanos. Y, también, en ellos mismos reconocen la capacidad de liderazgo que otros sujetos -como su esposa o sus hijos- buscan para tomar decisiones importantes, como lo puede ser la del voto.

De esta manera podemos observar que estas comunidades y estas figuras parecen representar, para los jefes de familia, los principales insumos para interpretar lo que ven por televisión sobre las elecciones y para, eventualmente, ejercer su participación política. Estas figuras coinciden con las que son reconocidas por este género como las expertas sobre la política: las masculinas, y debido al reconocimiento que tienen en la esfera pública. 
Ello es una evidencia de las limitaciones ideológico culturales que van unidas a las creencias, valores y comportamientos que históricamente han incorporado y reproducido estos varones y la sociedad en general. Éstos se han ido construyendo sobre las bases que domina el habitus de la cultura mexicana y que, según se ha revisado en el planteamiento y verificado a través de estos datos, tiene una incidencia directa en la participación de estos sujetos en el proceso comunicativo que aquí se ha analizado. En conclusión, entiendo que su identidad de género es definitoria en la forma en que se relacionan con la televisión.

\section{REFLEXIONES FINALES}

Una vez que se han expuesto los hallazgos y discutido los argumentos, la principal conclusión que se desprende de este trabajo es que la categoría de género comporta un lugar clave para el análisis de los procesos comunicativos.

Una vez que se definió tener como observable la participación de los jefes de familia en el proceso de recepción televisiva, lo que se ha constatado a lo largo de estas páginas es que la identidad de género les determina formas concretas de entender la realidad social y de relacionarse con los mensajes televisivos.

En primer lugar, este trabajo ha mostrado que la elección de sus fuentes de información encuentra una relación directa con su identidad de género. Se ha observado de qué manera pertenecer a la esfera pública influye a estos hombres en la elección que hacen de tipos de diarios y de lugares de lectura. Así también, explica su preferencia por los telediarios que han sido expuestos. Ello explica que sintonicen preferentemente las emisiones nocturnas de estos programas, porque es el momento en el que ha finalizado su jornada laboral.

Su identidad también les determina lugares, hábitos y prácticas de recepción televisiva. De acuerdo a los testimonios recogidos, su recepción tiene lugar en el espacio doméstico principal: la sala. Así también, sus hábitos se ven acompañados por las actividades relacionadas con el significado que tiene el hogar para el jefe de familia que, de acuerdo a lo aquí revisado, se convierte en un lugar de descanso en el que recibe atención (nutrición, servicio, respeto y satisfacción de sus necesidades). 
De la misma forma, las relaciones de poder, que hacen alusión a la dominación masculina de la que es condición fundamental su identidad de género, median de manera central los hábitos de recepción de estos jefes de familia -de que la selección de los telediarios que miran habitualmente dependa de ellos, de que sean los ocupantes habituales del sofá central y hasta del monopolio sobre el uso del control remoto-.

Todo ello ilustra que la participación de este grupo de audiencia, en el proceso de recepción televisiva que aquí se ha analizado, es activa. Tomando como base la valoración positiva que hacen de la actividad de informarse como un deber ciudadano, los jefes de familia que han participado en este estudio elaboran reflexiones críticas en torno a los acontecimientos. En primer lugar, a partir de los recursos que les proveen las fuentes de información señaladas. A partir también de la discusión de estos temas en los espacios en los que habitualmente socializan y que ha presentado al espacio público (el transporte público, el lugar de trabajo, el bar) como el primordial. Así también, de las figuras que ellos reconocen como líderes de opinión y que, en todos casos, se trata de masculinas. Y primordialmente, a partir de su experiencia de vida concreta.

Es por eso que los hallazgos discutidos en este trabajo dan razones para considerar la categoría de género como una pieza clave en la reflexión en torno a los fenómenos comunicativos. En este sentido, si bien la presente investigación permitió conocer algunos aspectos de este fenómeno, considero que todavía son muchos los elementos de análisis a explorar. Por ello sugiero como posibles líneas de investigación a continuar en el ámbito de nuestra disciplina:

- El análisis de los procesos de recepción televisiva de jefes de familia, en contraste con el de hombres con identidades de género distintas (jóvenes, estudiantes, profesionistas, etcéteras).

- El análisis de estos procesos en comparación con los de colectivos femeninos, de manera que permitan tener una visión más amplia sobre el papel que desempeña la identidad de género en estos procesos. Si algo queda claro es que los grupos de audiencia, constituidos por mujeres y por hombres con intereses bien diversos, participan de manera activa en los procesos socio-históricos. Lo que se requiere entonces es que promovamos la apertura de espacios para que todas las formas de ser sujeto puedan ser reconocidas. 


\section{BIBLIOGRAFÍA}

ABARCA, H. (1999) Discontinuidad en el modelo hegemónico de masculinidad, manuscrito, Santiago de Chile: FLACSO.

JENSEN, K. (1995) The Social Semiotics of Mass Communication, London, Sage.

- (1992) "El análisis de la recepción: la comunicación de masas como producción social de significado", en Jensen, K. y Jankowski, N. (eds.), Metodologías cualitativas de investigación en comunicación de masas, Barcelona: Bosch, pp. 165-180.

- (1987) "Qualitative Audience Research. Towards an Integrative Approach to Reception", en Critical Studies in Mass Communication, vol. 4, núm. 1, pp. 21-36.

LULL, J. (1990) Inside Family Viewing: Etnographic Research on Television's Audiences, London: Routledge

MARTíN-Barbero, J. (1990) De los medios a las mediaciones, México: Gustavo Gili.

MORLEY, D. (1986) Family Television, Londres: Comedia/Routledge.

- (1980), The 'Nationwide' Audience. Structure and Decoding, British Film Institute, London: BFI.

OROZCO, G. (1996) Televisión y audiencias: un enfoque cualitativo, Madrid: Ediciones de la Torre.

RAMíreZ, R. (1993) Dime Capitán, San Juan: Ediciones Huracán.

SILVERSTONE, Roger (1996) Televisión y vida cotidiana, Buenos Aires: Amorrortu.

VEGA, A. (2004) La decisión de voto de las amas de casa mexicanas y las noticias electorales televisadas. Tesis de Doctorado, Barcelona, España: Universidad Autónoma de Barcelona, .

- (2004a) "Forjando ciudadanía: Mujeres y participación política en México", en Hacia la construcción de una Ciencia de la Comunicación en México. Ejercicio reflexivo 1979-2004, México: Asociación Mexicana de Investigadores de la Comunicación.

Fecha de recepción: 21/04/2005. Aceptación: 12/05/2005. 